\title{
Front Matter: Volume 9920
}

, "Front Matter: Volume 9920," Proc. SPIE 9920, Active Photonic Materials VIII, 992001 (9 December 2016); doi: 10.1117/12.2258690

SPIE Event: SPIE Nanoscience + Engineering, 2016, San Diego, California, United SPIE. States 


\title{
PROCEEDINGS OF SPIE
}

\section{Active Photonic Materials VIII}

\author{
Ganapathi S. Subramania \\ Stavroula Foteinopoulou \\ Editors
}

28 August-1 September 2016

San Diego, California, United States

Sponsored and Published by

SPIE 
The papers in this volume were part of the technical conference cited on the cover and title page. Papers were selected and subject to review by the editors and conference program committee. Some conference presentations may not be available for publication. Additional papers and presentation recordings may be available online in the SPIE Digital Library at SPIEDigitallibrary.org.

The papers reflect the work and thoughts of the authors and are published herein as submitted. The publisher is not responsible for the validity of the information or for any outcomes resulting from reliance thereon.

Please use the following format to cite material from these proceedings:

Author(s), "Title of Paper," in Active Photonic Materials VIII, edited by Ganapathi S. Subramania, Stavroula Foteinopoulou, Proceedings of SPIE Vol. 9920 (SPIE, Bellingham, WA, 2016) Six-digit Article CID Number.

ISSN: 0277-786X

ISSN: 1996-786X (electronic

ISBN: 9781510602311

ISBN: 9781510602328 (electronic)

Published by

SPIE

P.O. Box 10, Bellingham, Washington 98227-0010 USA

Telephone +1 3606763290 (Pacific Time) · Fax +1 3606471445

SPIE.org

Copyright (c) 2016, Society of Photo-Optical Instrumentation Engineers.

Copying of material in this book for internal or personal use, or for the internal or personal use of specific clients, beyond the fair use provisions granted by the U.S. Copyright Law is authorized by SPIE subject to payment of copying fees. The Transactional Reporting Service base fee for this volume is $\$ 18.00$ per article (or portion thereof), which should be paid directly to the Copyright Clearance Center (CCC), 222 Rosewood Drive, Danvers, MA 01923. Payment may also be made electronically through CCC Online at copyright.com. Other copying for republication, resale, advertising or promotion, or any form of systematic or multiple reproduction of any material in this book is prohibited except with permission in writing from the publisher. The CCC fee code is 0277-786X/16/\$18.00.

Printed in the United States of America.

Publication of record for individual papers is online in the SPIE Digital Library.

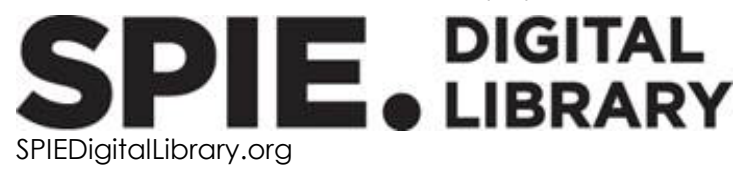

Paper Numbering: Proceedings of SPIE follow an e-First publication model. A unique citation identifier (CID) number is assigned to each article at the time of publication. Utilization of CIDs allows articles to be fully citable as soon as they are published online, and connects the same identifier to all online and print versions of the publication. SPIE uses a six-digit CID article numbering system structured as follows:

- The first four digits correspond to the SPIE volume number.

- The last two digits indicate publication order within the volume using a Base 36 numbering system employing both numerals and letters. These two-number sets start with 00, 01, 02, 03, 04, 05 , $06,07,08,09,0 A, 0 B \ldots$.. 0Z, followed by 10-1Z, 20-2Z, etc. The CID Number appears on each page of the manuscript. 


\title{
Contents
}

\author{
$\checkmark \quad$ Authors \\ vii Conference Committee \\ xi Introduction
}

EXTRAORDINARY ABSORPTION AND THERMAL PHENOMENA II

9920 OB Upper limits to near-field radiative heat transfer: generalizing the blackbody concept (Invited Paper) [9920-10]

NEW PARADIGMS FOR LASING AT THE NANOSCALE II

9920 OG Random lasing from a colloidal gain medium with urchin-like $\mathrm{TiO}_{2}$ structures [9920-15]

NEW FABRICATION METHODS AND DYNAMIC CONTROL OF PHOTONIC MATERIALS

$9920 \mathrm{OL}$ A first-principles study of the transition metals doped ZnSe crystal synthesized by vapor phase thermal diffusion method [9920-20]

GRAPHENE AND 2D MATERIALS FOR ACTIVE PHOTONICS

9920 OP Nonlinear plasmonic resonances in graphene nanostructures (Invited Paper) [9920-24]

NEW METHODS FOR DESIGNING AND PROBING EXOTIC PHOTONIC ENVIRONMENTS FOR EMITTERS

9920 OW Quasinormal mode approach to modeling light-matter interactions in plasmonic-dielectric cavity systems (Invited Paper) [9920-32]

9920 0X Collective behavior of quantum resonators coupled to a metamaterial [9920-33]

TOWARDS INTEGRATED PHOTONICS FOR QUANTUM INFORMATION

992012 Coupling of single NV center to the tapered optical fiber [9920-38]

$992014 \quad$ NV-based quantum memories coupled to photonic integrated circuits (Invited Paper) [9920-40] 
NON-HERMITIAN PHOTONICS I

$99201 \mathrm{M}$ Parity-time symmetry breaking in optically coupled semiconductor lasers (Best Student Paper) [9920-58]

992010 PT symmetry breaking in the presence of random, periodic, long-range hopping [9920-60]

NON-HERMITIAN PHOTONICS II

9920 IR Nonlinear reversal of PT-symmetric phase transition in a system of coupled micro-ring cavities (Invited Paper) [9920-63]

9920 IT Active asymmetric plasmonic Bragg gratings (Invited Paper) [9920-65]

$99201 \mathrm{~A} \quad$ Axisymmetric photonic structures with PT-symmetry (Invited Paper) [9920-66]

NOVEL PHOTONIC SYSTEMS FOR SENSING, SWITCHING, TUNEABLE RESPONSE, AND MODULATION I

9920 IY Unidirectional reflectionless propagation and slow-light enhanced sensing with plasmonic waveguide-cavity systems (Invited Paper) [9920-71]

992012 Ultrathin high-contrast optical modulators for visible and near infrared applications [9920-72]

NOVEL PHOTONIC SYSTEMS FOR SENSING, SWITCHING, TUNEABLE RESPONSE, AND MODULATION II

992024 Analytical method for the sensitivity analysis of active nanophotonic devices [9920-76]

992025 Towards liquid crystalline elastomer optically tunable photonic microstructures [9920-77]

POSTER SESSION

992026 Design, synthesis, and characterization of photoinitiators for two-photon polymerization [9920-78]

992027 Terahertz plasmon amplification in RTD-gated HEMTs with a grating-gate [9920-80]

992029 Ultrafast switching based on field optical bistability in nano-film of semiconductor [9920-82]

iv 


\section{Authors}

Numbers in the index correspond to the last two digits of the six-digit citation identifier (CID) article numbering system used in Proceedings of SPIE. The first four digits reflect the volume number. Base 36 numbering is employed for the last two digits and indicates the order of articles within the volume. Numbers start with 00, 01, 02, 03, 04, 05, 06, 07, 08, 09, OA, OB...0Z, followed by 10-12, 20-2Z, etc.

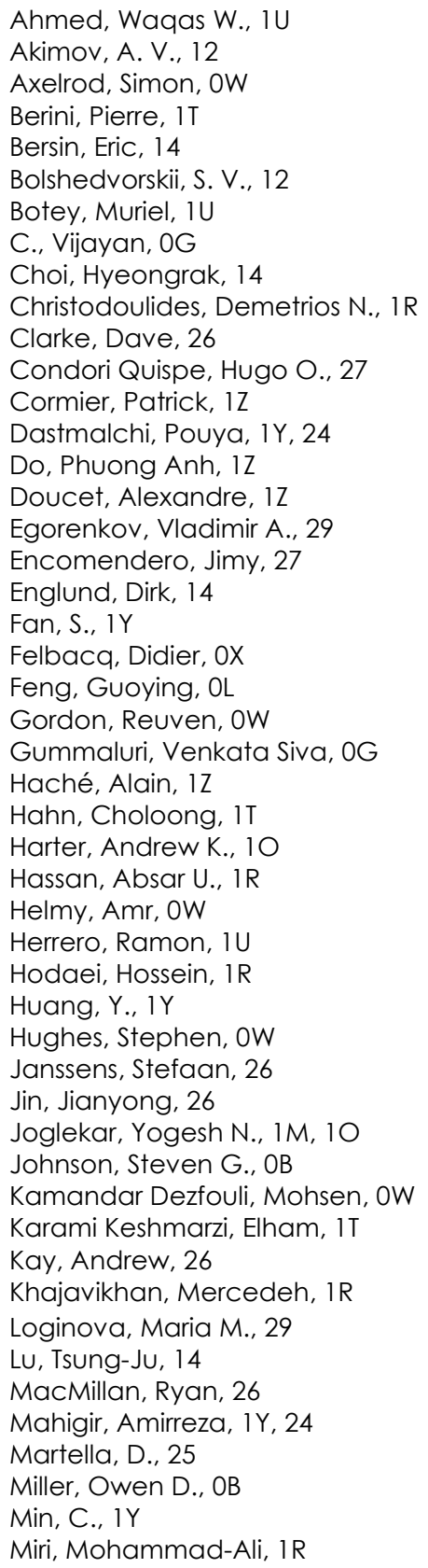

Mouradian, Sara, 14

Nair, Radhika V., OG

Nocentini, S., 25

Oh, Cha Hwan, $1 T$

Onanga, Franck Assogba, 10

Panoiu, Nicolae C., OP

Parmeggiani, C., 25

Raymond, Sebastiampillai, 26

Rodriguez, Alejandro W., OB

Rousseau, Emmanuel, OX

Schröder, Tim, 14

Sensale Rodriguez, Berardi, 27

Shin, W., IY

Simpson, Cather M., 26

Smolyaninov, A. N., 12

Son, Tran Vinh, $1 Z$

Song, Seok Ho, $1 T$

Sorokin, V. N., 12

Soshenko, V. V., 12

Staliunas, Kestutis, $1 U$

Suelzer, Joseph S., $1 \mathrm{M}$

Tait, R. Niall, IT

Thibodeau, Jacques, 12

Trofimov, Vyacheslav A., 29

Truong, Vo-Van, 12

Vemuri, Gautam, $1 \mathrm{M}$

Veronis, Georgios, 1Y, 24

Vorobyov, V. V., 12

Walsh, Michael, 14

Wan, Noel, 14

Wang, Herman M. K., OW

Weismann, Martin, OP

Whitby, Reece, 26

Wiersma, D. S., 25

Xing, Huili Grace, 27

You, Jian Wei, OP

Zanotto, S., 25

Zhang, Yuqin, OL

Zheng, Jiabao, 14

Zhou, Shouhuan, OL 
Proc. of SPIE Vol. $9920992001-6$

Downloaded From: https://www.spiedigitallibrary.org/conference-proceedings-of-spie on 26 Apr 2023 Terms of Use: https://www.spiedigitallibrary.org/terms-of-use 


\title{
Conference Committee
}

\author{
Symposium Chairs
}

Harry A. Atwater, Jr., California Institute of Technology (United States)

Nikolay I. Zheludev, Optoelectronics Research Centre

(United Kingdom) and Nanyang Technological University

(Singapore)

Symposium Co-chairs

David L. Andrews, University of East Anglia (United Kingdom)

James G. Grote, Air Force Research Laboratory (United States)

Conference Chairs

Ganapathi S. Subramania, Sandia National Laboratories

(United States)

Stavroula Foteinopoulou, The University of New Mexico (United States)

Conference Program Committee

Koray Aydin, Northwestern University (United States)

Paul V. Braun, University of Illinois at Urbana-Champaign

(United States)

Che Ting Chan, Hong Kong University of Science and Technology

(Hong Kong, China)

Zhigang Chen, San Francisco State University (United States)

Shanhui Fan, Stanford University (United States)

Didier Felbacq, Université Montpellier 2 (France)

Stephen Hughes, Queen's University (Canada)

A. Femius Koenderink, FOM Institute for Atomic and Molecular Physics (Netherlands)

Alexander V. Kildishev, Purdue University (United States)

Yuri S. Kivshar, The Australian National University (Australia)

Cefe López, Consejo Superior de Investigaciones Científicas (Spain)

Nicolae-Coriolan Panoiu, University College London

(United Kingdom)

Michelle L. Povinelli, The University of Southern California

(United States)

Christophe Sauvan, Laboratoire Charles Fabry (France)

Jörg Schilling, Martin-Luther-Universität Halle-Wittenberg (Germany)

Gennady B. Shvets, The University of Texas at Austin (United States)

Volker J. Sorger, The George Washington University (United States) 
Andrey A. Sukhorukov, The Australian National University (Australia)

Kosmas L. Tsakmakidis, University of California, Berkeley (United States)

Georgios Veronis, Louisiana State University (United States)

Daniel M. Wasserman, University of Illinois at Urbana-Champaign (United States)

Ralf B. Wehrspohn, Fraunhofer-Institut für Werkstoffmechanik (Germany)

William Whelan-Curtin, University of St. Andrews (United Kingdom)

\section{Session Chairs}

1 Recent Advances in Optoelectronics: New Architectures for Detectors and Sources

Ganapathi S. Subramania, Sandia National Laboratories (United States)

2 Extraordinary Absorption and Thermal Phenomena I

Sanjay Krishna, The University of New Mexico (United States)

3 Extraordinary Absorption and Thermal Phenomena II

Ting Luk, Sandia National Laboratories (United States)

4 New Paradigms for Lasing at the Nanoscale I

Michelle L. Povinelli, The University of Southern California (United States)

5 New Paradigms for Lasing at the Nanoscale II

Jesper Mork, Technical University of Denmark (Denmark)

6 New Fabrication Methods and Dynamic Control of Photonic Materials

Volker J. Sorger, The George Washington University (United States)

7 Graphene and 2D Materials for Active Photonics

Paul V. Braun, University of Illinois at Urbana-Champaign (United States)

8 Novel Platforms for Non-classical Light I

Boubacar Kante, University of California, San Diego (United States)

9 New Methods for Designing and Probing Exotic Photonic Environments for Emitters

Ganapathi S. Subramania, Sandia National Laboratories (United States) 
10 Towards Integrated Photonics for Quantum Information Simeon Bogdanov, Purdue University (United States)

11 Novel Platforms for Non-classical Light II

A. Femius Koenderink, FOM Institute for Atomic and Molecular Physics (Netherlands)

12 Topological Photonics I

Yuri S. Kivshar, The Australian National University (Australia)

13 Topological Photonics II

Andrea Alù, The University of Texas at Austin (United States)

14 Topological Photonics III

Zhigang Chen, San Francisco State University (United States)

15 Non-Hermitian Photonics I

Che Ting Chan, Hong Kong University of Science and Technology (Hong Kong, China)

16 Non-Hermitian Photonics II

Avadh Saxena, Los Alamos National Lab. (United States)

17 Uncovering New Physics in Interactions of Emitters with their Environment

Pierre Berini, University of Ottawa (Canada)

18 Novel Photonic Systems for Sensing, Switching, Tuneable Response, and Modulation I

Anders Kristensen, DTU Nanotech (Denmark)

19 Novel Photonic Systems for Sensing, Switching, Tuneable Response, and Modulation II

Hou-Tong Chen, The Center for Integrated Nanotechnologies

(United States) 
Proc. of SPIE Vol. $9920992001-10$

Downloaded From: https://www.spiedigitallibrary.org/conference-proceedings-of-spie on 26 Apr 2023 Terms of Use: https://www.spiedigitallibrary.org/terms-of-use 


\section{Introduction}

The science of light enabled extra-ordinary technologies that benefit a broad range of activities in our everyday lives such as telecommunications and computing, medical diagnostic methods, solid state lighting, and energy harvesting. To be able to utilize light's tremendous potential we must be able to tame and control its path in both space and time. Research with new structuredmaterial platforms continues to break new frontiers in photonics. The vast potential of such platforms is enriched with the incorporation of active as well as dynamically tunable materials, such as gain media, materials with nonlinear or time-dependent optical properties as well as quantum emitters.

The Active Photonic Materials VIII conference brought together the newest developments in the fundamentals and applications of structured-material platforms for active, dynamic, and tunable control of light. There were many exciting talks in the growing field of topological photonics that reported unprecedented control over the light's path, such as unidirectional and scatterfree properties. This is enabled in these systems by channeling light into states that are protected by the system's topology and can find applications in photonic circuitry and quantum information systems.

Photonic quantum information systems were also a central theme of the conference with emphasis on non-classical light generation and guiding. In addition, a number of fascinating talks focused on non-Hermitian photonic systems, were a balanced interplay between gain and loss manifests itself in paritytime (PT) symmetry, and is exploited for unidirectional propagation and lasing. Moreover, interesting talks reported also on different novel lasing paradigms that are based on Fano- or plasmonic resonant systems or utilize light localization in randomly structured media.

Furthermore, interesting topics presented in the conference included platforms for extra-ordinary tailoring of the absorption/emission, energy harvesting and harnessing near-field heat transfer. Last but not least, a number of talks focused on tunable or switchable photonic devices enabled with atomically thin materials, such as graphene, phase-change materials such as VO2, the incorporation of liquid crystalline elastomers (LCE), electrochromic polymers, or even dynamically tunable materials, such as Al-doped zinc oxide.

Our conference also ran a best student paper competition, recognizing the best contributed presentation that was presented by a student author. We would like to thank all student contributors for their enthusiasm with which they participated in this competition presenting outstanding and interesting results! The finalist winner of this competition, listed below, was presented with an SPIE award certificate at the conference's closing. 
Paper 9920-58, "Parity-time symmetry breaking in optically coupled semiconductor lasers," Joseph S. Suelzer, Yogesh N. Joglekar, Gautam Vemuri, Indiana Univ.-Purdue Univ. Indianapolis (United States).

Active Photonic Materials VIII has brought together theorists and experimentalists to exchange state-of-the art results in this rapidly evolving area of research. As conference chairs, we would like to express our sincere thanks to all the participants of the 9920 conference who contributed with their presentations as well as manuscripts to make this conference a stimulating and vibrant event.

\section{Ganapathi S. Subramania Stavroula Foteinopoulou}

